\title{
Awareness of labour analgesia among antenatal women in semi urban area
}

\author{
Poomalar G. K.*, Lakshmi Sameera
}

\begin{abstract}
Department of Obstetrics and Gynaecology, Sri Manakula Vinayagar Medical College and Hospital, Pondicherry,
\end{abstract} India

Received: 29 May 2016

Revised: 03 July 2016

Accepted: 04 July 2016

\author{
*Correspondence: \\ Dr. Poomalar GK, \\ E-mail: poomalarpragash@gmail.com
}

Copyright: (c) the author(s), publisher and licensee Medip Academy. This is an open-access article distributed under the terms of the Creative Commons Attribution Non-Commercial License, which permits unrestricted non-commercial use, distribution, and reproduction in any medium, provided the original work is properly cited.

\begin{abstract}
Background: Women's experience of pain during delivery varies greatly. Various pharmacological and nonpharmacological methods of labour analgesia are available. In spite of availability of various methods, even now women deliver with severe pain without adequate pain relief. The aim of the study was to determine the awareness of pregnant women about labour analgesia in semi urban setting.

Methods: This cross sectional study was done among 256 pregnant women attending antenatal out-patient in obstetrics and gynecology department. Antenatal women who were planned for elective cesarean section were excluded from the study.

Results: Out of 256 women $89.8 \%$ had no idea about usage of pain relief in labour. Only $10.2 \%$ had some idea about pain relief in labour. In previous delivery, $38.9 \%$ experienced severe pain, $58.4 \%$ experienced moderate pain and only $2.7 \%$ experienced mild pain. Some form of analgesia was administered to $89.9 \%$ of women. In spite of analgesia being given for majority, more number of women experienced moderate and severe pain (97.3\%). On analyzing various factors, order of pregnancy, income and occupational status had statistically significant influence on knowledge about labour analgesia.

Conclusions: There is a lack of knowledge among pregnant women about pain relief. Due to hectic work in labour room setting in India, it may be difficult to provide one to one care. Non-pharmacological methods should be popularized for pain relief. Usage of some form of pain relief will help in improving quality of care during labour and better outcome of mother and baby.
\end{abstract}

Keywords: Labour analgesia, Pharmacological method, Non-pharmacological method

\section{INTRODUCTION}

Delivery is a natural phenomenon accompanied with pain. Women's experience of pain during labour varies greatly. Some women feel little pain while others feel extremely distressing pain during labour.

A woman's position in labour, mobility, fear and anxiety may have an influence on severity of pain. Pain originates from different sites during first and second stage of labour. In the first stage, pain due to cervical dilatation is transmitted via spinal nerves T10-L1. Labour pain can be referred to the abdominal wall, low back, buttock and thighs. In second stage of labour, pain occurs from distension of the vagina, perineum, and pelvic floor. Pain is transmitted via the pudendal nerves, entering the spinal cord via nerve roots S2-S4. Woman also experiences rectal pressure and an urge to push during second stage.

Various pharmacological methods of labour analgesia include epidural analgesia, injections and inhalational agents. ${ }^{1}$ Alternative non-pharmacological approaches are 
transcutaneous electrical nerve stimulation, hydrotherapy, acupuncture, massage, aromatherapy and psycho prophylactic methods (hypnosis, biofeedback, yoga, and music therapy). ${ }^{1}$ In spite of availability of various methods, even now women deliver with severe pain without adequate pain relief. Lack of awareness among pregnant women is an important reason for nonutilization of analgesic techniques. Aim of our study was to determine the awareness of pregnant women about labour analgesia in semi urban setting.

\section{METHODS}

This cross-sectional study was done in the department of obstetrics and gynecology outpatient department, Sri Manakula Vinayagar medical college and hospital from Jan 2016 to March 2016. Sample size is calculated according to formula $4 \mathrm{pq} / \mathrm{d} 2$ where $\mathrm{p}=$ proportion of people with awareness; $\mathrm{q}=100-\mathrm{p}$; $\mathrm{d}=$ absolute precision (available error) which is 5\%. In a previous study proportion of people with awareness is 20\%. By calculating the values the sample size is 256 .

Pregnant women attending antenatal outpatient department were included in the study. Women who were planned for elective caesarean were excluded from the study. After getting consent from the pregnant women, they were personally interviewed using structured questionnaire. Proforma consisted of socio demographic characteristics, opinion about intensity of labour pain, knowledge about methods of pain relief and source of information about pain relief. In case of multi gravida, time duration for last delivery, the amount of pain experienced in previous delivery, usage of any pain relief during labour were collected. Other factors such as their preferred method of labour analgesia and reason for not opting for labour analgesia were also collected.

Results are reported in percentages. Socio demographic factors such as age, religion, educational status, order of pregnancy, income, occupation of the women were analyzed for their influence on awareness of labour analgesia. Delivery factors such as amount of pain expected in present delivery, amount of pain experienced in previous delivery, time duration of previous delivery were also analyzed for influence on acquiring knowledge on labour analgesia. Chi square test was used to assess various factors influencing knowledge on labour analgesia. $P$ value $<0.05$ was considered statistically significant.

\section{RESULTS}

Out of 256 women $89.8 \%$ had no idea about usage of pain relief in labour. Only $10.2 \%$ had some idea about pain relief in labour (Figure 1). In previous delivery, out of 149 women, $89.9 \%$ of women were given some form of analgesia during labour. Only $10.1 \%$ stated that they were not given any method of analgesia (Figure 2). But, $38.9 \%$ experienced severe pain, $58.4 \%$ experienced moderate pain and only $2.7 \%$ experienced mild pain during previous delivery (Figure 3). In spite of labour analgesia being given in majority of women, more number of women experienced moderate and severe pain $(97.3 \%)$ during labour.

Table 1: Demographic characteristic of study population.

\begin{tabular}{|c|c|c|}
\hline $\begin{array}{l}\text { Demographic characteristic of } \\
\text { study population }\end{array}$ & $\mathrm{N}=256$ & $\%$ \\
\hline \multicolumn{3}{|l|}{ Age } \\
\hline$<20$ years & 12 & $4.7 \%$ \\
\hline 20 - 30 years & 214 & $83.6 \%$ \\
\hline$>30$ years & 30 & $11.7 \%$ \\
\hline \multicolumn{3}{|l|}{ Educational status } \\
\hline Uneducated & 16 & $6.3 \%$ \\
\hline Schooling & 157 & $61.3 \%$ \\
\hline College & 83 & $32.4 \%$ \\
\hline \multicolumn{3}{|l|}{ Gravid } \\
\hline Primi & 107 & $41.8 \%$ \\
\hline Multi & 149 & $58.2 \%$ \\
\hline \multicolumn{3}{|l|}{ Income } \\
\hline$<10000$ & 227 & $88.7 \%$ \\
\hline $10000-50000$ & 26 & $10.2 \%$ \\
\hline$>50000$ & 3 & $1.1 \%$ \\
\hline \multicolumn{3}{|l|}{ Occupation } \\
\hline Housewife & 240 & $93.8 \%$ \\
\hline Employed & 16 & $6.2 \%$ \\
\hline
\end{tabular}

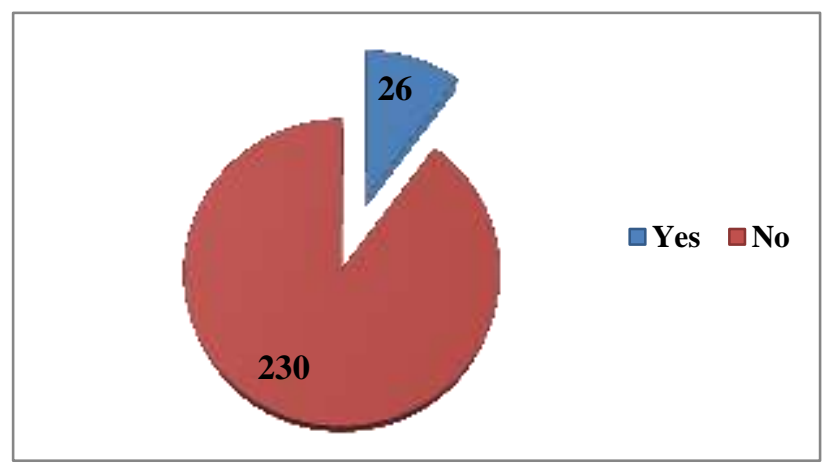

Figure 1: Knowledge about labour analgesia.

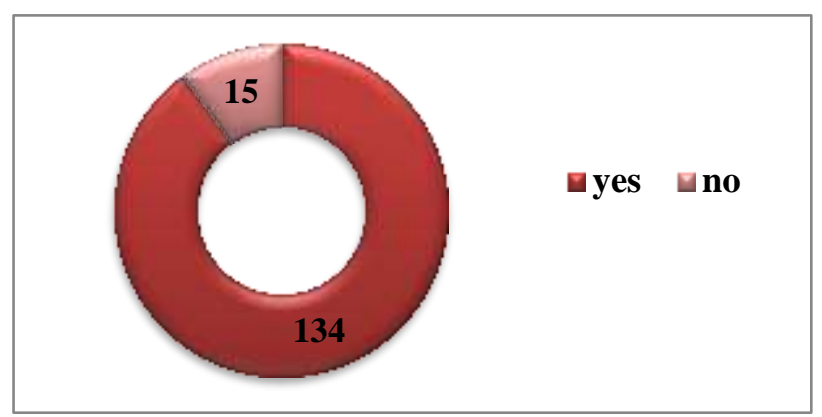

Figure 2: Number of women given labour analgesia in previous pregnancy. 


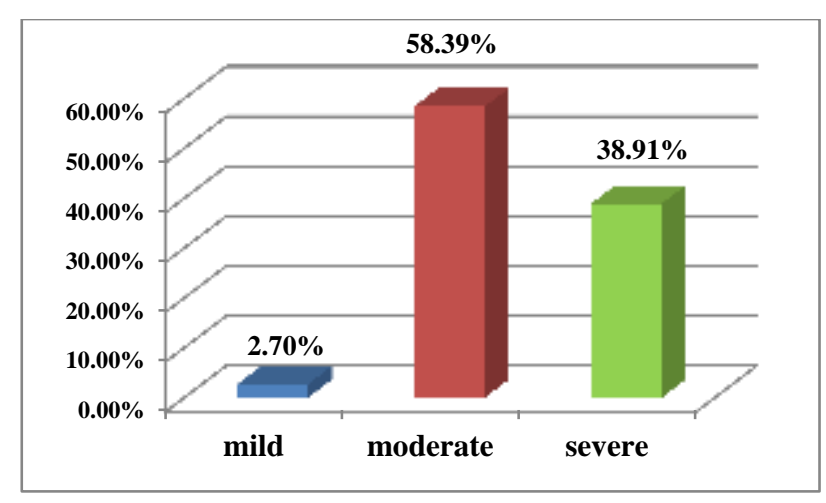

Figure 3: Severity of labour pain experienced in previous pregnancy.

Table 2: Socio demographic factors influencing knowledge on labour analgesia.

\begin{tabular}{|c|c|c|c|c|}
\hline $\begin{array}{l}\text { Knowledge on } \\
\text { labour } \\
\text { analgesia }\end{array}$ & $\begin{array}{l}\text { Yes } \\
(\mathrm{N}=\mathbf{2 6})\end{array}$ & $\begin{array}{l}\text { No } \\
(\mathrm{N}=230)\end{array}$ & $x^{2}$ & $P$ value \\
\hline \multicolumn{5}{|l|}{ Age } \\
\hline$<20$ years & 0 & 12 & \multirow{3}{*}{1.44} & \multirow{3}{*}{0.487} \\
\hline 20 - 30 years & 23 & 191 & & \\
\hline$>30$ years & 3 & 27 & & \\
\hline \multicolumn{5}{|l|}{ Religion } \\
\hline Hindu & 17 & 180 & \multirow{3}{*}{2.63} & \multirow{3}{*}{0.268} \\
\hline Muslim & 8 & 47 & & \\
\hline Christian & 1 & 3 & & \\
\hline \multicolumn{5}{|c|}{ Educational status } \\
\hline Uneducated & 1 & 15 & \multirow{3}{*}{0.311} & \multirow{3}{*}{0.856} \\
\hline Schooling & 16 & 141 & & \\
\hline college & 9 & 74 & & \\
\hline \multicolumn{5}{|l|}{ Gravid } \\
\hline Primi & 6 & 101 & \multirow{2}{*}{4.17} & \multirow{2}{*}{$0.041 *$} \\
\hline Multi & 20 & 129 & & \\
\hline \multicolumn{5}{|c|}{ Income (INR/month) } \\
\hline$<10000$ & 19 & 208 & \multirow{3}{*}{7.32} & \multirow{3}{*}{$0.026 *$} \\
\hline $10000-50000$ & 6 & 20 & & \\
\hline$>50000$ & 1 & 2 & & \\
\hline \multicolumn{5}{|l|}{ Occupation } \\
\hline Housewife & 22 & 218 & \multirow{2}{*}{4.12} & \multirow{2}{*}{$0.042 *$} \\
\hline employed & 4 & 12 & & \\
\hline
\end{tabular}

On analysing various socio demographic factors, age, religion, educational status of women did not have influence on knowledge about labour analgesia significantly. On analysing order of pregnancy, multigravida had a better knowledge than primigravida ( $\mathrm{x} 2$ value 4.17 ; p value $0.041 *$ ). Similarly women with income of $>$ Rs.10000/month had a better knowledge than those with < Rs.10000/month ( $\mathrm{x} 2$ value $7.32 ; \mathrm{p}$ value $\left.0.026^{*}\right)$. Similarly employed women had a better knowledge than housewife ( $\mathrm{x} 2$ value $4.12 ; \mathrm{p}$ value $0.042 *$ ) (Table 2).

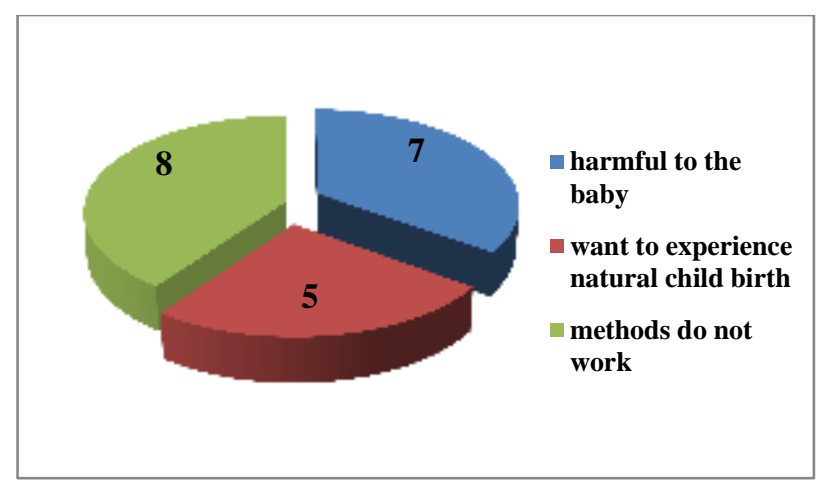

Figure 4: Reason for not opting for labour analgesia.

Table 3: Delivery factors influencing knowledge on labour analgesia.

\begin{tabular}{|c|c|c|c|c|}
\hline $\begin{array}{l}\text { Knowledge on } \\
\text { labour } \\
\text { analgesia }\end{array}$ & Yes & No & $x^{2}$ & $\begin{array}{l}\mathbf{P} \\
\text { value }\end{array}$ \\
\hline $\begin{array}{l}\text { Severity of } \\
\text { pain expected } \\
\text { in present } \\
\text { delivery }\end{array}$ & $\mathrm{N}=26$ & $\mathrm{~N}=230$ & & \\
\hline Mild & 15 & 174 & \multirow{4}{*}{7.94} & \multirow{4}{*}{$0.047^{*}$} \\
\hline moderate & 8 & 50 & & \\
\hline Severe & 1 & 1 & & \\
\hline No idea & 2 & 5 & & \\
\hline $\begin{array}{l}\text { Duration of } \\
\text { labour in last } \\
\text { delivery }\end{array}$ & $\mathrm{N}=23$ & $\mathrm{~N}=126$ & & \\
\hline$<4$ hours & 6 & 26 & \multirow{4}{*}{1.86} & \multirow{4}{*}{0.601} \\
\hline $4-12$ hours & 4 & 23 & & \\
\hline $12-24$ hours & 6 & 22 & & \\
\hline$>24$ hours & 7 & 55 & & \\
\hline $\begin{array}{l}\text { Severity of } \\
\text { pain during } \\
\text { previous } \\
\text { delivery }\end{array}$ & $\begin{array}{l}\text { Yes } \\
\mathrm{N}=23\end{array}$ & $\begin{array}{l}\text { No } \\
N=126\end{array}$ & & \\
\hline Mild & 1 & 3 & \multirow{3}{*}{2.01} & \multirow{3}{*}{0.365} \\
\hline Moderate & 16 & 71 & & \\
\hline Severe & 6 & 52 & & \\
\hline
\end{tabular}

On analysing delivery related factors, women those who expected moderate and severe pain had statistically significant knowledge about labour analgesia than those who expected mild pain in present delivery ( $\mathrm{x} 2$ value 7.94; p value $0.047 *$ ). Other factors like duration of labour in previous delivery and severity of pain in previous delivery did not have significant influence on knowledge about labour analgesia (Table 3).

Only 26 pregnant women had prior knowledge about labour analgesia. Out of it 24 got information from 
friends and relatives. Out of 256 pregnant women, $51.3 \%$ considered injections as preferred method for analgesia. One woman preferred inhalational method and $40.6 \%$ would opt for the method which doctor advices. $7.8 \%$ of women were against labour analgesia. Seven out of 20 women who were against labour analgesia, thought that it may cause harm to the baby. Some did not believe that they cause pain relief ( 8 out of 20) and other women wanted to experience natural child birth (5 out of 20) (Figure 4).

\section{DISCUSSION}

Delivery is the most painful experience in women's life. McGill pain questionnaire comparing pain scores for women in labour and other painful conditions, shows that labour pain is more severe than cancer pain and it is almost close to the pain experienced due to amputation of digit. $^{2}$ On comparing different types of pain, regardless of the psychophysical method used, cancer pain, myocardial infarction pain, renal colic pain, burn pain, and labour pain were considered as the most intensive pain. ${ }^{3}$

The modern era of labour analgesia began in 1847 when Dr J. Y. Simpson administered ether to a woman during childbirth. Since then usage of labour analgesia made the women to deliver with less pain. This labour pain not only causes distress to the mother, it also has influence on the labour progress and fetal outcome. Acute stress during labour activates the sympathetic nervous system, resulting in an increase in plasma catecholamine levels. This increased catecholamine levels during labour, are associated with decrease in uterine blood flow. ${ }^{4,5}$ This results in fetal hypoxia. Severe pain, anxiety and increased catecholamine levels are associated with prolonged or dysfunctional labour. ${ }^{6}$

In the year 2008, US statistics shows that 61 percent of women delivered vaginally received epidural or spinal anaesthesia. ${ }^{7}$ But in India, awareness and usage of adequate analgesia technique was very low compared to western statistics. Our study showed only $10.2 \%$ of pregnant women had some idea about pain relief in labour. Many other studies done in India also showed awareness level of $<10 \%$. $^{8-10}$

In previous delivery, out of 149 women nearly $97 \%$ experienced moderate to severe pain. $89.9 \%$ of women were given intramuscular injections during labour. Only $10.1 \%$ stated that they were not given any method of analgesia. This shows intramuscular injections given during labour does not produce pain relief in labour. Cochrane analysis shows that up to two-thirds of women who received opioids reported moderate or severe pain following administration of analgesia. ${ }^{11}$

In this study, on analyzing various socio demographic factors and delivery related factors, factors such as order of pregnancy, family income, occupational status of women and severity of pain expected in present pregnancy had statistically significant influence on knowledge about labour analgesia than others.

Only 26 pregnant women in our study had prior knowledge about labour analgesia. Out of it, 24 got information from friends and relatives. This shows that health care workers do not provide adequate counseling about labour pain and about the options of labour analgesia during routine antenatal checkups. Because of overwhelming crowd in antenatal out-patient department, it may not be possible to provide counseling about labour analgesia in Indian settings.

In this study, $7.8 \%$ of women were against labour analgesia. Reason being harmful to the baby, no belief that they cause complete pain relief and some wanted to experience natural child birth. Even educated people believe that delivery cannot occur without pain. Because of this deep rooted belief that delivery is painful, either patients are unaware of labour analgesia or failed to utilize these pain relieving methods.

Due to ever rising population in India, there is a lack of one to one care during deliver resulting in inability to provide optimal labour analgesia. There should be mass media coverage for proving information about labour analgesia, to increase awareness and acceptance of labour analgesia. Women should be informed about options of labour analgesia well in advance in antenatal period by a counselor. House visits by village health nurses may be utilized for providing information about labour analgesia. Leaflets containing details on labour analgesia during antenatal visits can be another option for reducing the burden of counseling.

Pregnant women should be given options of various pain reliefs, both about pharmacological and nonpharmacological labour analgesia. Systemic opiods such as pethidine, tramadol, fentanyl, remifentanil can be used for pain relief in labour. Though they are easy to administer, there are concerns about maternal effects such as sedation, hypoventilation, hypotension, prolonged labour, urine retention, nausea and vomiting. Also there is a concern about elimination of pethidine, and its metabolite from fetus, which may take even three to six days. It may lead to respiratory depression, decreased alertness and delayed effective breastfeeding in them. Although neonates can completely metabolize tramadol, mothers receiving tramadol had higher pain scores when compared to pethidine. ${ }^{12}$ Among inhalational analgesics, only nitrous oxide (in $50 \%$ oxygen) is widely used for analgesia in modern obstetric practice. It has various disadvantages. It is ineffective in up to half of parturient. Occupational exposure to nitrous oxide is a concern among labour room staff, which may lead to loss of fertility, miscarriage and anomalies in them. ${ }^{13}$ Epidural analgesia, produces most effective form of pain relief. ${ }^{14}$ Absence of pain during labour allows enjoyment and control of labour. Epidural analgesics have certain disadvantages like requirement of continuous cardio 
tocographic monitoring, requires resident anesthesia, cardio-respiratory facilities and increased rate of instrumental delivery.

Pharmacological methods of pain relief may not be possible, because of low doctor patient ratio in India. At least non-pharmacological methods should be popularized among pregnant women and should make use of it which may provide pain relief and improvement in labour satisfaction. ${ }^{1}$ Among various nonpharmacological interventions tried, methods such as water immersion, massage, acupuncture and relaxation relieved pain and improved labour satisfaction and childbirth experience. ${ }^{1}$ There is insufficient evidence to make judgments on whether or not hypnosis, biofeedback, sterile water injection, aromatherapy or transcutaneous electrical nerve stimulation are more effective than placebo or other interventions for pain management in labour. ${ }^{1}$

Studies have shown that continual support throughout the whole labour reduces the length of labour, the use of medication for pain relief, the caesarean rate, and the use of oxytocin. ${ }^{15,16}$ A Cochrane review found that women who had continuous support during labour were more likely to have a shorter labour, spontaneous vaginal birth and less need for analgesia. ${ }^{17}$

Fear of labour pain is an important reason for increase in rate of caesarean section at maternal request. Fear of labour pain leading to request for caesarean section in as many as $66.5 \%$, as shown in a study done among Turkish women. ${ }^{18}$ If labour analgesia techniques are utilized routinely, it may help in better handling of labour pain. Better pain relief leads to good labour outcome, which may indirectly reduce the rate of caesarean section.

\section{CONCLUSION}

In spite of the presence of various pain relief techniques, women deliver with moderate to severe pain in labour. This is due to lack of adequate knowledge among pregnant women about pain relief and hectic work in labour room in Indian setting. Awareness is especially lacking among women in semi urban setting. Nonpharmacological methods should be popularized among pregnant women, which may provide pain relief and satisfaction during labour. Creating awareness may help them improve usage of adequate analgesia, which may in turn improve quality of care during labour and better outcome of mother and baby.

Funding: No funding sources Conflict of interest: None declared

Ethical approval: The study was approved by the Institutional Ethics Committee

\section{REFERENCES}

1. Jones L, Othman M, Dowswell T, Alfirevic Z, Gates $\mathrm{S}$, Newburn M, et al. Pain management for women in labour: an overview of systematic reviews. Cochrane Database of Syst Rev. 2012;3:CD009234.

2. Melzack R. The myth of painless childbirth (the John J. Bonica lecture). Pain. 1984;19:321-37.

3. Priscilla H, Érika Z, Faleiros SFAE. Validation of the ratio scale of the differents types of pain. Rev Latino-Am Enfermagem. 2008;16(4):720-6.

4. Lederman RP, McCann DS, Work B, Huber MJ. Endogenous plasma epinephrine and norepinephrine in last-trimester pregnancy and labor. Am J Obstet Gynecol. 1977; 129(1):5-8

5. Shnider SM, Abboud T, Artal R, Henriksen EH, Stefani SJ, Levinson G. Maternal catecholamines decrease during labor after lumbar epidural analgesia. Am J Obstet Gynecol. 1983;147:13-5.

6. Lederman RP, Lederman E, Work B, McCann DS. Anxiety and epinephrine in multiparous labor: relationship to duration of labor and fetal heart rate pattern. Am J Obstet Gynecol. 1985;153(8):870-7.

7. Osterman MJK, Martin JA. Epidural and spinal anesthesia use during labor: 27-state reporting area, 2008. National vital statistics reports; 59(5). Hyattsville, MD: National Center for Health Statistics. 2011;59(5):1-16.

8. Naithani U, Bharwal P, Chauhan SS, Kumar D, Gupta S, Kirti. Knowledge, attitude and acceptance of antenatal women toward labor analgesia and caesarean section in a medical college hospital in India. J Obstet Anaesth Crit Care. 2011;1:13-20.

9. Shidhaye RV, Galande MV, Bangal VB, Joshi SS, Shidhaye UR. Awareness and attitude towards labour analgesia of Indian pregnant women. Anaesth Pain and Intensive Care. 2012;16(2):131-6.

10. James JN, Prakash KS, Ponniah M. Awareness and attitudes towards labour pain and labour pain relief of urban women attending a private antenatal clinic in Chennai, India. Indian Journal of Anaesthesia. 2012;56(2):195-8.

11. Ullman R, Smith LA, Burns E, Mori R, Dowswell T. Parenteral opioids for maternal pain relief in labour. The Cochrane database of systematic reviews. 2010;(9):CD007396.

12. Claahsen-van der Grinten HL, Verbruggen I, van den Berg PP, Sporken JM, Kollée LA. Different pharmacokinetics of tramadol in mothers treated for labour pain and in their neonates. Eur $\mathbf{J}$ Clin Pharmacol. 2005;61:523-9.

13. Henderson K, Matthews I, Adisesh A, Hutchings A. Occupational exposure of midwives to nitrous oxide on delivery suites. Occupational and Environmental Medicine. 2003;60(12):958-61.

14. Anim-Somuah M, Smyth RM, Jones L. Epidural versus non-epidural or no analgesia in labour. Cochrane Database Syst Rev. 2011;12:CD000331.

15. Bruggemann OM, Parpinelli MA, Osis MJD, Cecatti JG, Neto ASC. Support to woman by a companion of 
her choice during childbirth: a randomized controlled trial. Reproductive Health. 2007;4:5.

16. Brüggemann OM, Parpinelli MA, Osis MJD. Evidence on support during labor and delivery: a literature review. Cad Saúde Pública. 2005;21:131627.

17. Hodnett ED, Gates S, Hofmeyr GJ, Sakala C, Weston J. Continuous support for women during childbirth. Cochrane Database of Syst Rev. 2011;3:CD003766.

18. Aksoy M, Aksoy AN, Dostbil A, Celik MG, Ince I. The relationship between fear of childbirth and women's knowledge about painless childbirth. Obstet Gynecol Int. 2014;2014:274303.

Cite this article as: Poomalar GK, Sameera L. Awareness of labour analgesia among antenatal women in semi urban area. Int J Reprod Contracept Obstet Gynecol 2016;5:2612-7. 